use and some pollution sources have been noticed during the environmental investigations, although no emanation at a toxic level was detected. The psychosocial investigations emphasised a real suffering of the agents and a communication problem towards the events.

The results allowed us to make some recommendations which are currently being applied. Since the beginning of their application, no more complaints have been reported.

\section{PARA-OCCUPATIONAL LEAD EXPOSURE IN CHILDREN OF WORKERS IN FACTORIES USING LEAD}

${ }^{1} \mathrm{D}$ J Jeannel, ${ }^{2}$ Thos, ${ }^{3}$ Titton, ${ }^{2}$ Allain, ${ }^{2}$ Yemadje, ${ }^{4}$ Precausta, ${ }^{5}$ Albouy. ${ }^{1}$ Orléans, France; ${ }^{2}$ InVS regional office Cire Centre, Orléans, France; ${ }^{3}$ Health agency of Centre region, Orléans, France; ${ }^{4}$ Occupational medicine, Pithiviers, France; ${ }^{5}$ Dirrecte, Orléans, France

\subsection{6/oemed-2013-101717.28}

Objectives After reporting 2 children lead poisoning (>100 mg/ L), environmental investigation identified parental occupational exposure as the most likely source. A cross-sectional survey was implemented in September 2010, its aim was to estimate and analyse the para-occupational exposure of employee's children of two factories in the Centre Region (France) and their subcontractors.

Methods Children were screened for blood lead level on a voluntary basis. Individual and family data on potential lead exposure were collected using a questionnaire and analysed using SAS ${ }^{\circ}$ 9.1. Risk factors for lead contamination were identified using univariate logistic regression.

Results Overall, 87 children from 0 to 18 years ( 40 boys and 47 girls) with at least one parent occupationally exposed to lead, were screened (participation rate was 31.5\%). Arithmetic and geographic means of blood lead levels were respectively 34.2 $\mathrm{mg} / \mathrm{L}$ and $26.9 \mathrm{mg} / \mathrm{L}$. The prevalence of contamination (between 50 and $99 \mu \mathrm{g} / \mathrm{L}$ ) was $17.2 \%$ and that of intoxication $(\geq 100 \mu \mathrm{g} / \mathrm{L})$ is $1.15 \%$. Risk factors for contamination were age under $6(\mathrm{RR}=$ $2.11 \mathrm{p}=0.09)$ and living in a home built before $1948(\mathrm{RR}=$ $3.96 \mathrm{p}=0.02)$. Children under 6 had a blood lead level average of $46.9 \mathrm{mg} / \mathrm{L}$, significantly higher than that of children aged 6-12 and 12-18 (respectively 32.4 and $25.1 \mathrm{mg} / \mathrm{L}$ ). A significant correlation was observed between blood lead level of children and that of their exposed parent $(\mathrm{p}<0.001)$.

Conclusion The geometric mean of blood lead levels (26.9) in these children with occupationally exposed parents was nearly twice higher than that observed in the Centre region $(14.7 \mathrm{mg} / \mathrm{L})$ and similar to those obtained in the framework of the national monitoring blood lead levels in children in 2005-2007 $(33.6 \mathrm{mg} /$ L), which targets at-risk children. This confirms existence of exposure to lead in these children of workers in factories using lead.

\section{Session: E. Sustainable employability}

\section{WHAT EFFECT DOES LIVER TRANSPLANT IN ADULTS HAVE ON EMPLOYMENT? - A SYSTEMATIC REVIEW}

${ }^{1} \mathrm{R}$ Waclawski, ${ }^{2}$ Noone. ${ }^{1}$ University of Alberta, Edmonton, Canada; ${ }^{2}$ Health Service Executive Dublin North East, Dublin, Ireland

\subsection{6/oemed-2013-101717.29}

Objectives Return to work after liver transplantation was last reviewed in 2000. Changes have occurred to transplant programmes since that time. As such, a review of recent publications was undertaken to identify if the employment experience has altered in the past 12 years.

Methods A literature search was performed in PubMed and Embase. Papers published from January 2000 to December 2011 in the English language were included in the review. 181 papers were identified. After removal of duplicates 117 abstracts and titles were screened and 29 papers considered for eligibility. 24 papers were included in this review.

Results 10 papers were from the USA and 14 were from other countries. The number of cases followed up ranged from 8 to 471 (total 3,222 ) with a mean age of 51.9 years. The follow-up period ranged from 2 to 20 years (mean 6.1 years). 10 studies included pre and post-transplant employment rates. Pre-transplant rates ranged from $40-75 \%$ (mean 63.8\%). Post-transplant the rates ranged from 22-57\% (mean 37.1\%). In 9 studies the employment rate fell. Posttransplant employment rates fell with duration of follow-up (7 studies; $\mathrm{p}=0.016$ ). Cross-sectional analysis showed recipients had lower physical component scores on SF-36 compared to the general population. Longitudinal data showed improvement in physical function between pre- and post-transplant assessment. The results were lower than the general population but better than those with chronic liver disease. One paper identified depression as a factor associated with higher unemployment post-transplant.

Conclusions The review indicates that post transplantation employment rates are lower compared to pre-transplantation rates, despite improved physical function. Rates appear to fall with duration of follow-up over the first 6.5 years after transplantation. A study with follow-up at intervals after transplantation would improve understanding of the return to work issues and help plan suitable interventions.

\section{PREDICTORS OF PROLONGED WORK PARTICIPATION IN WORKERS WITH AND WITHOUT CHRONIC DISEASE: A 3-YEAR PROSPECTIVE COHORT STUDY}

${ }^{1} \mathrm{C}$ R L Boot, 'Deeg, 'Abma, 'Rijs, ${ }^{1}$ van Tilburg, ${ }^{1}$ van der Beek. 'VU University Medical Center, Amsterdam, Nederland; ${ }^{2}$ VU University, Amsterdam, Nederland

\subsection{6/oemed-2013-101717.30}

Objectives The workforce is shrinking, as more people retire than start their career. It is therefore important to maintain older workers in the workforce. The prevalence of chronic disease increases with age. It is unknown whether predictors of prolonged work participation differ between workers with and without chronic disease. The aim of this study was to investigate differences and similarities in predictors of prolonged work participation in workers aged $55+$ years with and without chronic disease.

Methods All workers aged 55-62 years were selected from the 2002-2003 cohort of the Longitudinal Ageing Study Amsterdam $(\mathrm{n}=333)$. Potential predictors at baseline were: health, personality, work characteristics, and demographics. Per potential predictor, a logistic regression coefficient for involvement in paid work in 2005/2006 was calculated, separately for workers with and without chronic disease. Next, a pooled estimate was constructed. Using a $\chi^{2}$ test for coefficients, differences between the pooled estimate and the coefficients were tested.

Results The prevalence of chronic disease was 59\% and 67\% was still involved in paid work three years later. Follow up data was available of 316 workers (95\%). Physical workload $\left(\chi^{2}: 5.37 ; \mathrm{DF}=1\right)$ and psychosocial resources at work $\left(\chi^{2}\right.$ : 5.94 ; DF1 $=$ ) differed between the groups with and without 